\title{
Hombres que ejercen violencia conyugal. Estado actual del abordaje institucional en la provincia de Concepción, Chile ${ }^{1}$
}

\author{
Men who use spousal violence. Current status of \\ institutional approach in the province of Concepción, Chile
}

\begin{abstract}
Tatiana Sanhueza Morales. Académica Escuela Trabajo Social, Universidad de Concepción. Asistente social, doctora () Doctorado en servicio social (Universidad Laval, Québec, Canadä). Magister en estudios de Género y Cultura mención Ciencias Sociales (Universidad de Chile). Diplomada en Estudios de la Mujer (Universidad de Concepción). Barrio Universitario, Facultad de Ciencias Sociales, Departamento de Trabajo Social, Universidad de Concepción; tsanhueza@udec.cl

\section{Maruzzella Valdivia Peralta. Académica Departamento de Psicología, Universidad de Concepción. Psicóloga clínica. Magister en Psicología de la Salud (Universidad de Concepción). Barrio Universitario, Facultad de Ciencias Sociales, Departamento de Psicología, Universidad de Concepción; mavaldivia@udec.cl.}

Pierre Turcotte. Directeur École Service Social, Université Laval, Québec, Canadá. Trabajador social. Maitrise en sociologie (UQAM). Doctorat en service social (Université de Montréal). Pavillon Charles-De Koninck, bureau 5442-A. Université Laval. Québec (Québec) Canada G1V 0A6; Pierre.Turcotte@svs.ulaval.ca

\begin{abstract}
Resumen
El presente artículo es el resultado de una investigación realizada en la provincia de Concepción, Chile entre 2010 y 2011, con el objeto de conocer el estado actual del abordaje institucional en materia de hombres que ejercen violencia conyugal. La experiencia chilena de intervención de la violencia conyugal lleva más de dos décadas (desde 1990), sin embargo hay una intervención temprana dirigida a hombres que ejercen violencia que motiva el estudio. El estudio es de tipo exploratorio-descriptivo, con metodología mixta, en base a aplicación de cuestionarios y entrevistas semiestructuradas, dirigidas a profesionales y autoridades o jefes/as de servicios públicos. Los resultados exponen la ausencia de una politica pública que oriente el accionar de manera integral, exigua cantidad de programas especializados, escasa intervención en red y de acciones preventivas. Un cambio de paradigma, que incorpore la visión estructural y relacional de la problemática son considerados como elementos clave para potenciar de manera integral las intervenciones con hombres que ejercen violencia conyugal.

Palabras claves. Violencia conyugal, Politica pública, Agresores, Género, Trabajo social.

Abstract

This article is the result of research conducted in the province of Concepción, Chile (between 2010 and 2011), in order to know the current status of the institutional approach on men exercising domestic violence. The Chilean experience of domestic violence intervention has been practiced since more than two decades (from 1990); however, this study is focused in an early intervention targeting men who use violence. This study is exploratory-descriptive with mixed-methods, based on application of questionnaires and semi-structured interviews to professionals and authorities or utilities heads. The results reveal the absence of a public policy to guide the actions holistically, small amount of specialized programs, poor network intervention and preventive actions. A change of paradigm that incorporates the structural and relational view of the problem is considered key to comprehensively enhance interventions with men who exercise domestic violence.
\end{abstract}

Key words. Domestic violence, Public policies, aggressors, gender, social work.

1 Artículo desarrollado en el marco del Proyecto de Investigación DIUC Universidad de Concepción N²09.171.010.0. Se agradece la contribución de alumnas de la carrera de trabajo social y de la carrera de psicología de la Universidad de Concepción, quienes participaron en el proceso de recolección de datos. 


\section{Introducción}

Desde mediados de los años setenta, países de Europa como de América del Norte, han implementado estrategias para luchar contra la violencia conyugal hacia las mujeres. La promulgación de legislación específica, la creación de institucionalidad especializada, la implementación de servicios terapéuticos dirigidos tanto a víctimas como a quienes ejercen la violencia, así como acciones de prevención, han sido iniciativas impulsadas gracias a los movimientos feministas, al apoyo de instituciones internacionales y al rol que los Estados nacionales han asumido en materia de erradicación de la problemática.

Chile no ha sido la excepción, gracias al movimiento de mujeres en los años ochenta, el marco jurídico internacional, en especial el relativo a los Derechos humanos, así como los diversos instrumentos internacionales que nuestro país ha suscrito ${ }^{2}$, han jugado un rol fundamental para que el Estado venga desde la década del noventa realizando una serie de iniciativas para prevenir, reparar y sancionar la Violencia Intrafamiliar (VIF).

Dicho proceso ha experimentado una serie de etapas que dicen relación con el reconocimiento del fenómeno como un problema público; la creación de una institucionalidad responsable de elaborar y coordinar política pública en la materia (siendo el Servicio Nacional de la Mujer -SERNAM- a quien le corresponde dicha labor); la promulgación de dos leyes que sancionan la violencia al interior de las familias (ley 19.325 en 1994 y ley 20.066 en 2005); la sensibilización y capacitación a funcionarios de servicios públicos; la creación de programas de prevención, atención y protección a víctimas de $\mathrm{VIF}^{3}$; la inclusión de la problemática en políticas de un mayor número de sectores como División de Seguridad pública, Ministerio de Salud, Comisión Nacional de Estupefacientes, SERNAM, policías, Ministerio de Justicia, entre otros (Corporación DOMOS, 2010).

Dichas iniciativas han intentado responder a la magnitud del problema. En el último tiempo se ha producido en un alza en la denuncia: entre el año 1995 (con 38.200 denuncias VIF) al año 2007 (con 108.538 denuncias VIF), hubo un incremento de 284\%, en donde el 90\% de las denuncias tuvieron a la mujer como víctima (Corporación DOMOS, 2010). Según el Sistema de Automatización Policial (AUPOL) de denuncias y partes de Carabineros de Chile, en el primer trimestre del año 2014 las denuncias a nivel nacional eran 27.982 y en la Provincia de Concepción estas ascendían a 1.751 (Subsecretaria de Prevención del Delito, Ministerio del Interior y Seguridad Pública, 2014). Por otra parte, en el año 2013, el sistema AUPOL indicaba que de la población entre 18 y 65 y más años, 2.901 hombres y 563 mujeres fueron denunciados por ejercer violencia intrafamiliar con lesiones menos graves, graves o gravísimas. Por su parte, SERNAM registró en 2013 40 femicidios y a noviembre del año 2014 se han contabilizado 39 femicidios a nivel nacional y 89 femicidios frustrados (www.sernam.cl).

Las estadísticas expuestas anteriormente indican la prevalencia del problema social, así como la constatación de que los hombres ejercen mayoritariamente violencia conyugal hacia las mujeres, lo que justificaría ampliamente la necesidad de servicios disponibles para este grupo. No obstante, diagnósticos realizados respecto de la intervención dirigida a hombres con comportamientos violentos hacia sus parejas, daban cuenta de iniciativas implementadas con limitados fondos públicos y acciones autogestionadas por grupos de profesionales y algunas organizaciones de la sociedad civil. Como señala la Corporación DOMOS (2009), en su mayoría, de reducida cobertura, delimitadas a población de territorios locales específicos y con financiamientos de corto plazo. Por su parte, la respuesta estatal dirigida a este grupo social no diverge del diagnóstico expuesto, el "Plan Nacional de Acción para la Prevención de la Violencia Intrafamiliar en Chile. Septiembre 2011-Agosto 2012" (SERNAM, 2011) -que regía durante el tiempo que se desarrolló la investigación- no establecío ningún compromiso o acción focalizada destinada a los hombres que ejercieran violencia hacia su pareja. Aquellas experiencias existentes fueron aisladas, sin continuidad en el tiempo, lo que ha dificultado su evaluación así como la acumulación de experiencia y conocimiento en vista del mejoramiento de la oferta pública (Morales, Muñoz, Trujillo, Hurtado, Cárcamo, \& Torres, 2012).

2 Convención sobre la Eliminación de Todas las Formas de Discriminación contra la Mujer CEDAW (1979). Declaración sobre la Eliminación de la Violencia contra la Mujer (Asamblea General de Naciones Unidas, 1993). Convención Interamericana para Prevenir, Sancionar y Erradicar la Violencia contra la Mujer o Convención de Belem do Pará (1994)

3 A la fecha existen 96 Centros de la Mujer y 24 Casas de Acogida destinadas a mujeres víctimas de violencia intrafamiliar (www.sernam.cl).

4 Dicha estrategia se lograría a través de tres acciones concretas, indicándose sus respectivos organismos responsables: 1) Intervención con hombres que ejercen violencia en los 15 "Centros para hombres por una vida sin violencia". Responsable SERNAM. 2) Intervención con hombres que ejercen violencia en los 5 Centros de intervención de Gendarmería de Chile. 3) Talleres psico educacionales a imputados (hombres) por Fiscalía por hechos de violencia intrafamiliar a mujeres. Responsable Municipalidad de Santiago, Centro de Atención de la Familia. 
Es en el Plan Nacional de Acción para la Prevención de la Violencia Intrafamiliar en Chile. Noviembre 2012-Diciembre 2013, se plantea concretamente como una estrategia del Eje promoción y prevención la "Intervención con hombres que ejercen violencia a fin de generar conciencia del ejercicio de ésta, incentivar cambios sustentables en el tiempo y por ende, evitar futuras víctimas" (p.38)

Frente al escenario nacional expuesto anteriormente, la Provincia de Concepción, perteneciente a la Región del BioBío no es una excepción. Según la Encuesta Nacional de Victimización por Violencia Intrafamiliar y Delitos Sexuales (División de Seguridad Pública del Ministerio del Interior, 2013), esta última es una de las regiones que expone una de las más altas tasas de prevalencia en violencia intrafamiliar. La presente investigación surge entonces del interés de conocer qué recursos existen, qué se hace, cuales son las prácticas y las respuestas institucionales dirigidas hacia hombres que ejercen violencia en contexto de pareja en la Provincia de Concepción. A partir de un enfoque ecológico, el estudio pretende describir aquellos factores en el ámbito institucional que pudiesen estar contribuyendo en la agudización del problema social así como en su disminución. Como señala Smedslund (2014) la instauración de una práctica tiene limitaciones, resistencias y avances. Sostenemos que analizar dichos aspectos respecto de la problemática que nos concierne es coherente con un trabajo social que reflexiona sus prácticas para mejorarlas.

\section{Marco teórico-conceptual Definición}

La violencia conyugal es un alarmante problema social y de salud pública. La Organización Mundial de la Salud la considera un problema de alta prioridad en donde las acciones de prevención así como las medidas tomadas por los Estados en materia de salud, justicia y servicios sociales son fundamentales para su erradicación. Dentro de estos esfuerzos, la literatura especializada ha expuesto claramente la importancia en la definición de la problemática y el cambio de paradigma que su abordaje implica. Como señalaremos más adelante, la comprensión de esta afectará las políticas que se elaboren así como los organismos responsables, los modelos y prácticas utilizadas, las legislaciones que la sancionen, y finalmente, las representaciones sobre víctimas y agresores. (Harris, 2014; Lesieux, Rinfret-Raynor \& Brodeur, 2014; Smedslund, 2014).

Para efectos de esta investigación el equipo de estudio utiliza el concepto de violencia conyugal elaborado por el Centro de Investigación Interdisciplinaria sobre la Violencia Familiar y la Violencia Hacia las Mujeres (CRI-VIFF), el cual entiende la violencia conyugal "... como un ejercicio abusivo de poder por el cual un individuo en posición de fuerza busca controlar a otra persona utilizando diferentes medios con el fin de mantenerla en un estado de inferioridad o de obligarla a adoptar comportamientos conformes a sus propios deseos. Esta definición no se limita a las conductas individuales ya que la violencia puede ser ejercida en sistemas más amplios" ${ }^{15}$. Dos elementos son centrales en la comprensión del fenómeno y son aportados por esta definición. El primero es la importancia del abuso de poder, ya que como señala Lindsay y Clément (1998), en el dominio de la violencia familiar el término violencia remite habitualmente a la agresión física, mientras que el término "abuso" refiere a todas las formas de comportamiento utilizadas para mantener el miedo y la intimidación en la víctima así como el control y el poder en quien abusa. Existe lo que Stark (2014) concibe como "control coercitivo", que incluye aquella violencia aparentemente menor, comúnmente banalizada, minimizada, a pesar de ser la más común de las violencias vividas y que en muchos casos no es denunciada ni penalizada (por ejemplo humillación, aislamiento, control, imposición de reglas, entre otras).

Lo anterior es coherente con lo planteado por Adams (1988) quien señala que la violencia sería todo acto de "quien hace hacer a la víctima algo que ella no quiere, le impide hacer alguna cosa que ella quiere hacer, o provoca en ella miedo... poco importa si hay agresión física o no." (p.191). Esto no quiere decir que la agresión física y sus efectos no sean importantes (de hecho lo son), sin embargo comúnmente algunas definiciones han puesto el énfasis en las consecuencias físicas, lo que ha tenido implicancias en la legislación y por ende en la sanción de esta, invisibilizando muchas veces el patrón de abuso existente, exponiendo la violencia como eventos físicos y en donde los miembros de la pareja estarían en igualdad de condiciones.

5 «La violence est définie comme un exercice abusif de pouvoir par lequel un individu en position de force cherche à contrôler une autre personne en utilisant des moyens de différents ordres afin de la maintenir dans un état d'infériorité ou de l'obliger à adopter des comportements conformes à ses propres désirs. Cette définition ne se limite pas aux conduites individuelles puisque la violence peut s'exercer par des systèmes plus larges.» (www.criviff.qc.ca) (Traducción propia). 
Para el equipo de investigación es fundamental considerar la importancia de las relaciones de poder y de subordinación que son reproducidas en el proceso de socialización sexista en el cual los sujetos se construyen: así, las mujeres, debido a la posición de inferioridad social que poseen en relación a los hombres, tienen mayor riesgo de vivir experiencias de violencia así como sufrir las consecuencias más graves. (Damant et al., 2005; Stark, 2014; Yllö, 1988). Por tanto, según nuestra comprensión la violencia conyugal ejercida por un hombre hacia su pareja (mujer) no respondería a patrones simétricos ${ }^{6}$.

En segundo lugar -retomando la definición que aporta el CRI-VIFF- esta expone claramente que la violencia "no se limita a las conductas individuales" sino que estas se enmarcan en un contexto, en un sistema más amplio que da las bases para que los individuos establezcan este tipo de relaciones, lo que hemos llamado el nivel estructural de la problemática, sustentado en aspectos culturales y de representación.

\section{Enfoque ecológico}

La complejidad del fenómeno de la violencia conyugal expondría la existencia de raíces profundas en la cultura y en un sistema que la tolera. Uno de los modelos más ampliamente utilizados es el basado en la aplicación de los conceptos ecológicos de Brofenbrenner (1979), puesto que comprende la violencia como producto de variables en el Macrosistema, Exo-sistema, Microsistema y Ontogenético (individual). Dichos subsistemas se modulan entre sí de manera dinámica, recíproca y permanente, integrando la trama de factores sociales, culturales y psicológicos que generan y mantienen dicha violencia. Entonces, se puede entender la violencia conyugal considerando los elementos sistémicos asociados a ella y así entenderla (también) como un problema estructural ${ }^{7}$.

En términos breves, el Macrosistema remite a la ideología, las formas de organización social, los sistemas de creencias y los estilos de vida que preva- lecen en una cultura o subcultura en particular. Son patrones generalizados que impregnan los distintos estamentos de una sociedad y que podrían constituirse en factores de riesgo que toleren la violencia o en factores de protección que promuevan relaciones igualitarias entre hombres y mujeres (Dutton, 1995, citado en Stith. et al., 2004).

Resulta pertinente precisar que para el equipo de estudio, el análisis de género, definido como un "... elemento constitutivo de las relaciones sociales basadas en las diferencias sexuales, (y que) constituye una forma primaria de relaciones significantes de poder." (Scott, 1987) puede entregar luces respecto de las resistencias y los avances que las instituciones y la sociedad en general articulan para responder a un problema social ${ }^{8}$. Respecto de esto, el Informe del Programa de Naciones Unidas para el Desarrollo (PNUD, 2010), indica que tres (de los seis) factores en los que reposa el contexto de desigualdad de género en la sociedad chilena es la existencia, por un lado, de representaciones de género machistas y autoritarias; la violencia hacia las mujeres y una clara ausencia, tanto al interior de las políticas como de los debates públicos, del compromiso de los hombres a los cambios ligados a las relaciones de género. Como señala Turcotte (2014), los hombres constituyen un grupo de riesgo elevado para varias problemáticas sociales como el suicidio, la violencia conyugal, las toxicomanías y que se constata que una mínima cantidad consultan los servicios de ayuda (lo que principalmente se debe a causa de su socialización de género), en donde los hombres no parecen percibir rápidamente los problemas que viven y aún cuando toman conciencia de ello, prefieren no consultar sino como última instancia debido a una crisis personal o relacional. Entonces, podríamos preguntarnos de qué manera la construcción de una "masculinidad hegemónica"9 (Connell, 1995) que se ha impuesto como un deber ser para los hombres, fortaleciéndose en las prácticas individuales y colectivas de género, podría constituirse en un factor pertinente en el análisis de la respuesta institucional en materia de violencia conyugal.

El segundo nivel, Exosistema, estaría compuesto

6 Johnson (2005) justamente expone la controversia en el debate sobre la simetría de la violencia, es decir, la simetría implica que hombres y mujeres ejercen violencia por igual (Straus, 2005) versus la asimetría de la violencia en donde los hombres ejercerían mayoritariamente la violencia conyugal (Loseke \& Kurz, 2005; Damant \& Guay, 2005).

7 Para efectos de nuestra investigación resulta útil profundizar en aquellos aspectos del nivel macro y exosistema, puesto que nuestro foco de análisis (el escenario respecto de los servicios dirigidos a hombres con comportamientos violentos) remite a estos niveles.

8 La misma Scott propone analizar los cuatro elementos de su definición: 1) símbolos y representaciones culturales, 2) las normas sociales, 3) las nociones políticas, instituciones y organizaciones sociales y 4) la identidad subjetiva.

9 En donde ciertos atributos forman la base del concepto (dominación, control, fuerza, competición, determinación, triunfo, protección, heterosexualidad, entre otros), mientras otros atributos pasan a ser inferiores, menos aceptados o subordinados (sensibilidad, empatía, homosexualidad). 
por la comunidad más próxima e incluye las instituciones mediadoras entre el nivel de la cultura y el nivel individual: la escuela, la iglesia, los medios de comunicación, los ámbitos laborales, las instituciones recreativas, los organismos judiciales y de seguridad, la legislación en la materia así como el Estado a través de las políticas y servicios que implementa. Este nivel tendría una relación dinámica con el expuesto anteriormente, ya que, siguiendo a Merrien, Parchet \& Kernen (2005) respecto de que quienes deciden tomar medidas sociales se fundan en representaciones ideológicas y culturales que definen la situación de una cierta manera y las soluciones susceptibles de ser aplicadas, podríamos comprender que una política pública es una práctica social que es construida a partir de las representaciones del problema, de valores subyacentes en la sociedad y que al mismo tiempo puede fortalecerlos o generar cambios en los discursos y prácticas sociales. En este contexto, las instituciones que implementan acciones expresan la importancia que tiene cada uno de los sectores en un proyecto político determinado.

Si concebimos las políticas públicas no como respuestas a los problemas sino como intentos de mejorar las políticas anteriormente adoptadas, el acento se instala en el proceso invención/aprendizaje de las políticas. Este enfoque resulta interesante ya que nos permite preguntarnos y analizar en base a qué paradigma se sostiene una política determinada y cuál es el contexto o qué acontecimientos han influenciado el cambio de modelo y por tanto el cambio de política (Heclo, 1974. Citado en Merrien et al., (2005)). En definitiva, utilizar el enfoque de la política pública como una construcción social, permite considerar aquellos aspectos del contexto que influyen en su elaboración, mantención y pertinencia.

La experiencia internacional ha demostrado la importancia de la voluntad política, de la definición que se tenga de la problemática así como de la adaptación de las instituciones y de los funcionarios a las características de la violencia conyugal y de los sujetos a los cuales está dirigida la intervención (Harris, 2014; Lavergne, 1998; Smedslund, 2014; Turcotte, 2014). Una nueva forma de pensar la violencia se basaría en la alianza cooperativa institucional que considera erróneos las iniciativas aisladas, entendiendo la violencia conyugal con raíces estructurales y sociales en donde se necesita la colaboración de la sociedad entera (Smedslund, 2014).

El tercer nivel del modelo ecológico, el Microsistema, comprende la red de vínculos más próximos de un sujeto, por ejemplo la familia, la pareja, el grupo de amigos quienes cumplirían un rol importante en la vida de este así como en la aceptación o rechazo en la utilización de la violencia en la pareja.

Finalmente, el nivel Ontogenético, refiere el nivel individual de una persona, a cómo esta ha integrado aquellos elementos del nivel macrosocial, es decir, refiere sobre sus experiencias y sus actitudes frente a la violencia, la construcción de género (para los efectos de esta investigación, la masculinidad elaborada), aspectos cognitivos, conductuales, así como factores de riesgo (abuso de drogas ilegales, consumo abusivo de alcohol, depresión, entre otros) y factores de protección (niveles satisfactorios de empatía, resolución saludable de conflictos, actitudes favorables a las relaciones en igualdad entre hombres y mujeres) (Stith 2004). Extraído de Andrés-Pueyo, López \& Álvarez, 2008).

Según la definición adoptada por el equipo de investigación, tenemos una posición crítica respecto del término acuñado por la legislación chilena ${ }^{10}$, definición que centra el fenómeno en los efectos de la violencia y en los vínculos de parentesco, dejando de lado -según nuestro análisis- al menos tres aspectos: no incluye la violencia ocurrida en el seno de las relaciones amorosas -en donde no haya convivencia o un hijo en común-, que afecta mayoritariamente a adolescentes y jóvenes ${ }^{11}$. En segundo lugar, desde un enfoque ecológico: reduce la violencia a problemas familiares y descontextualiza que este tipo de violencia responda a sistemas más amplios que la sostienen y reproducen. Finalmente, se centra en el daño, lo que es importante como señalábamos pero, omite la raíz y el objetivo del uso de la violencia, es decir, que se trata de una forma de controlar al otro en base al abuso de poder y a sistemas desiguales de género, invisibilizándolo (el género) como un factor de riesgo (Lesieux et al., 2014; Stark, 2014)

10 "... todo maltrato que afecte la vida o la integridad física o psíquica de quien tenga o haya tenido la calidad de cónyuge del ofensor o una relación de convivencia con él; o sea pariente por consanguinidad o por afinidad en toda la línea recta o en la colateral hasta el tercer grado inclusive, del ofensor o de su cónyuge o de su actual conviviente. También habrá violencia intrafamiliar cuando la conducta referida en el inciso precedente ocurra entre los padres de un hijo común, o recaiga sobre persona menor de edad, adulto mayor o discapacitada que se encuentre bajo el cuidado o dependencia de cualquiera de los integrantes del grupo familiar." (Ley 20.066, art. 5).

11 El 16\% de una muestra de 8.352 jóvenes entre 15 y 29 anos, señala que ha tenido al menos alguna vez en su vida una situación de violencia en su relación de pareja (Séptima Encuesta Nacional de Juventud, 2012). 


\section{Objetivos}

Describir el estado actual del abordaje institucional en la Provincia de Concepción, con hombres que ejercen violencia conyugal, en base a los servicios existentes, los sistemas de derivación, así como los obstaculizadores y facilitadores identificados por los/as informantes respecto de dicha intervención.

\section{Metodología}

La investigación corresponde a un estudio de carácter exploratorio-descriptivo, transversal y sincrónico, el que fue realizado durante el período de tiempo correspondiente al año 2010 y 2011. Con un muestreo no probabilístico, ya que la selección de los informantes fue en base a la función desempeñada por los profesionales y autoridades que trabajan en instituciones relacionadas al abordaje de la violencia intrafamiliar y por la accesibilidad a los hombres (usuarios de programas terapéuticos).

Con el fin de enriquecer el estudio, se utilizó un enfoque mixto usando dos métodos de recolección de información: Un cuestionario que fue construido adhoc por las investigadoras y en el que se consideraba las características del abordaje de la violencia, las acciones implementadas y los equipos ejecutores. Este se aplicó a funcionarios y/o profesionales que desarrollaban funciones relacionadas a la problemática de la investigación. Inicialmente el equipo de investigación identificó 108 instituciones del sector público insertas en las doce comunas de la Provincia de Concepción que, según la Ley 20.066 cumplen un rol vinculado a la prevención, tratamiento y sanción de la Violencia Intrafamiliar. Así se identificaron cuatro áreas de abordaje hacia la problemática: el Sistema Judicial que debe dar cumplimiento a la ley y asegurar las garantías legales de la población. El sector Salud, que por ley debe abordar toda problemática psicosocial o de salud mental de la población. Carabineros de Chile, quien toma la denuncia, previene el delito, vela por el cumplimiento de las leyes, y finalmente Gendarmería de Chile, quien es la encargada de velar por el cumplimiento de la sanción legal y que además ejecutaba en ese momento un Programa Piloto de atención de hombres sancionados por VIF. La información obtenida se analizó utilizando el programa estadístico Statistical Package for the Social Sciences (SPSS), versión 18.0, exponiéndose los datos en términos de frecuencias y porcentajes.

El segundo método utilizado fue la entrevista semiestructurada dirigida a autoridades y/o jefes de servicios. Para asegurar la rigurosidad científica de la investigación, las entrevistas fueron grabadas y posteriormente transcritas de manera textual con el objeto de contar con un texto útil para el análisis. Se elaboró una malla temática, a partir de la cual se analizaron los elementos concernientes al objetivo de la investigación.

El equipo investigador considera la existencia de convergencia de información levantada a través de ambos métodos, complementándose desde distintos niveles (macro y micro) la exposición del escenario actual de los servicios hacia hombres que ejercen violencia hacia sus parejas. El reconocimiento de la violencia conyugal como un problema social, la estrecha relación entre el marco más amplio (Ley, política pública) y las prácticas de intervención institucional, convirtiéndose el primero (marco político y legal) en una limitante o en una oportunidad de las segundas (intervenciones institucionales). La importancia del trabajo intersectorial y las acciones aisladas de cada servicio. Una baja respuesta del Estado hacia los hombres que ejercen violencia hacia sus parejas. La existencia de diferencias en la cantidad de servicios en torno a los territorios y en cada institución. El compromiso de las instituciones y los funcionarios por responder adecuadamente a la problemática, así como los obstáculos y necesidades para lograr una respuesta satisfactoria (creación de programas especializados, capacitación en el tema, entre otros), fueron hallazgos recogidos en base a ambos métodos.

\section{Aspectos éticos}

Se informó a los participantes sobre las implicancias de la investigación, participando aquellos que accedieron voluntariamente a entregar información en forma fidedigna sobre la temática. Las investigadoras explicaron que el uso de la información se haría solo y exclusivamente para cumplir los objetivos del presente estudio.

\section{Resultados}

Los datos que a continuación se presentan son el resultado del análisis de 96 cuestionarios (42 del Sector Salud, 24 de Carabineros, 27 del Sistema Judicial y 3 de Gendarmería), así como de la información recogida en las 12 entrevistas semiestructuradas realizadas. Dicha información se expondrá de manera integrada puesto que brinda una tanto mirada macro como micro del escenario actual. La exposición se estructura según cuatro aspectos: los servicios existentes; los sistemas de derivación, los obstaculizadores y los facilitadores o avances identificados por los informantes.

\section{Los servicios existentes}

De las 96 instituciones que respondieron el estudio, 3 instituciones implementan un programa destinado específicamente al trabajo con hombres con 
comportamientos violentos en contexto de pareja (Hospital Higueras, Hospital Regional y Gendarmería). Sin embargo, el 32\% de las instituciones encuestadas cuentan con un equipo de profesionales para realizar acciones dirigidas a este grupo, aunque no implementan un programa específico.
El accionar desarrollado por las instituciones se clasificó en 11 funciones que en términos generales se describen a continuación:

Respecto de la primera función: Primer contacto, la Figura N 1 muestra que son los sectores Salud y Carabineros los que mayoritariamente la llevan a cabo. FIGURA No 1

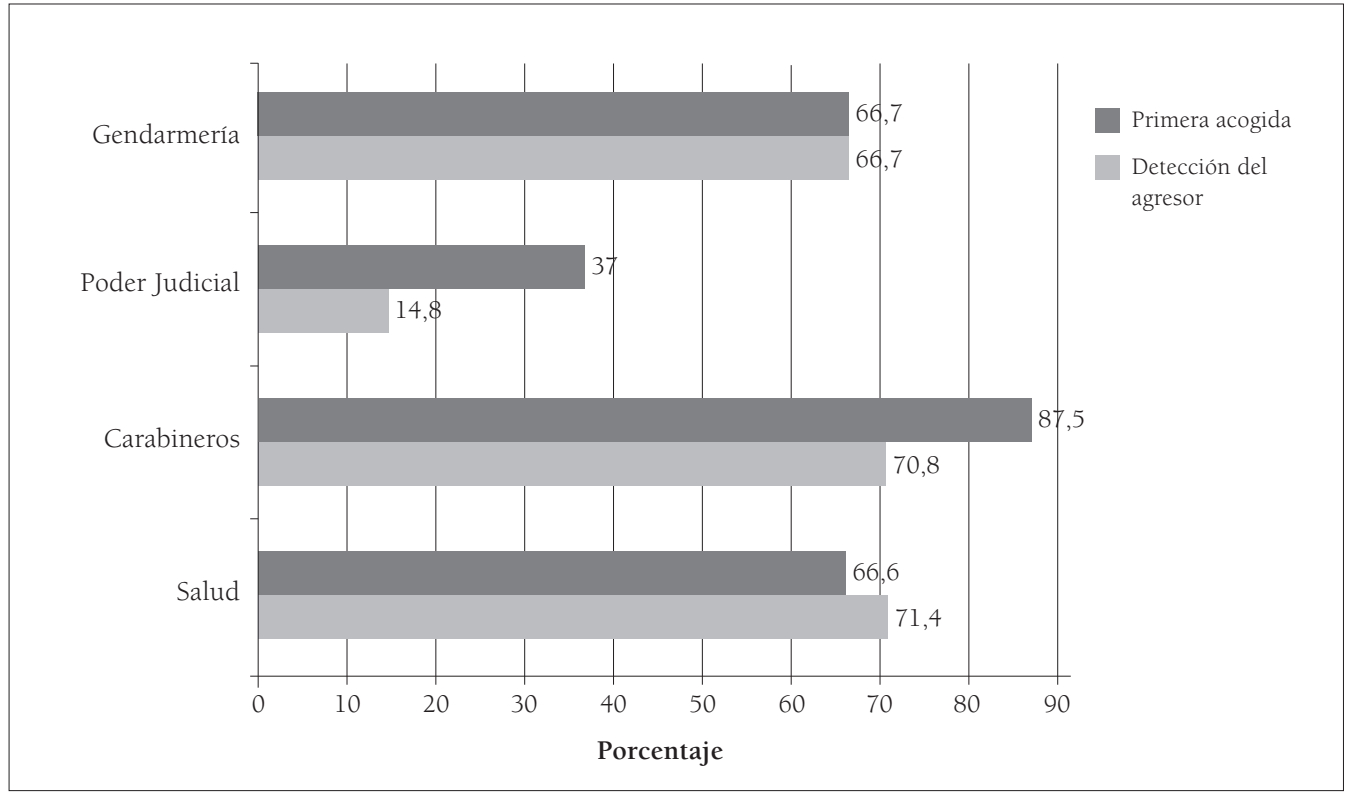

Fuente: elaboración propia.

En cuanto a la segunda función: Atención, la función específica más desarrollada por las diversas instituciones es la de la atención individual, siendo el sector Salud quien mayoritariamente la implementa (en más de un 70\%). (Figura N 2).

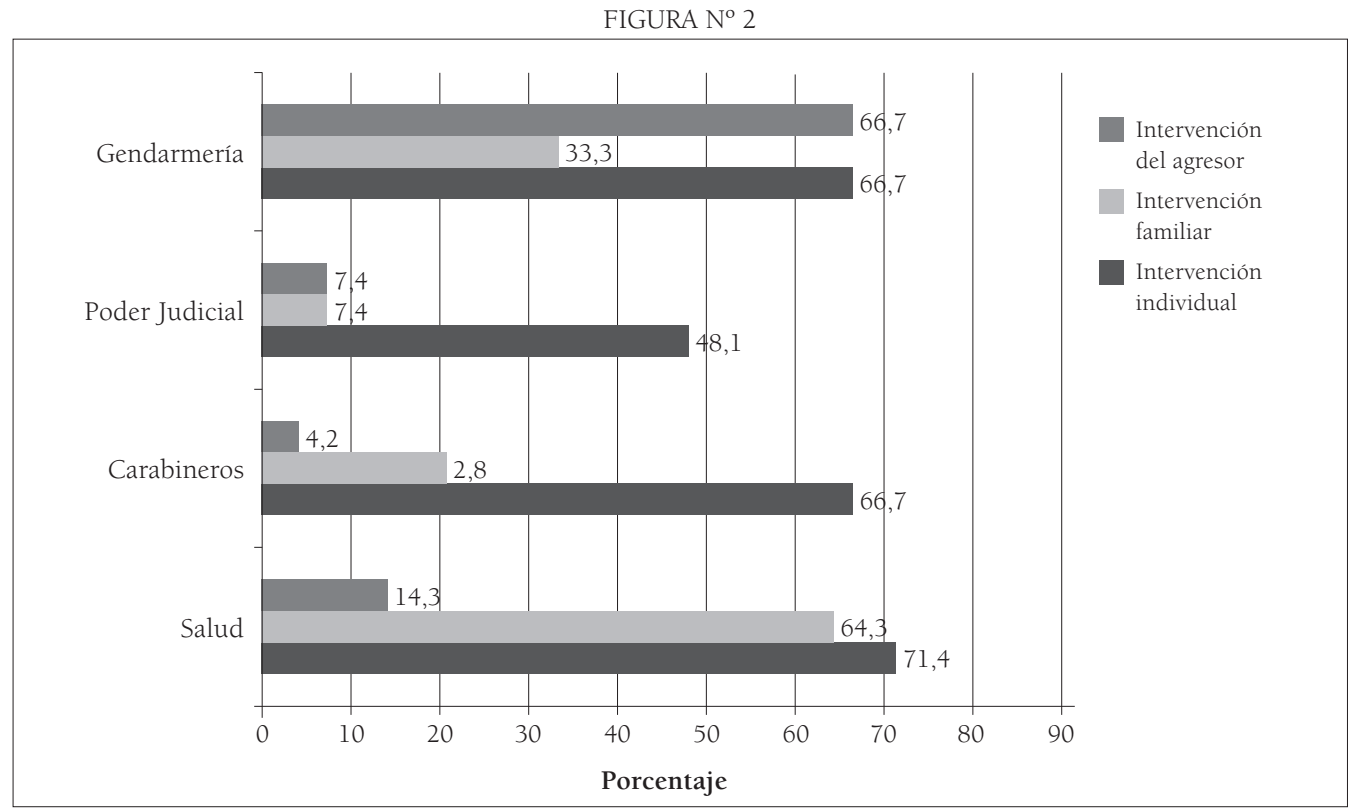

Fuente: elaboración propia. 
En relación a la tercera función: Trabajo en redes, la Participación en redes muestra un accionar similar entre las instituciones, entre 40\% y 50\% de ellas participan en dichas instancias. En cuanto a la Derivación a redes es Carabineros y el Sector judicial quienes en un $70 \%$ llevan a cabo esta acción.

Respecto de la cuarta función: Política pública, ninguno de los sectores participantes del estudio desarrollan las cuatro funciones específicas (planificación, implementación, seguimiento, evaluación) y quienes implementan alguna de estas, lo hacen en un porcentaje inferior al 25\%, a excepción de Gendarmería que en el $66 \%$ de sus programas lleva a cabo la Implementación y Seguimiento de política pública.
En materia legal: Asesoría legal (quinta función), tanto Salud como Carabineros y Gendarmería llevan a cabo la función específica de Orientación e Información legal. El sector judicial realiza en un 40\% al 60\% las acciones de Orientación e Información legal, Asesoría jurídica y Patrocinio jurídico. En cuanto a la sexta función (Aplicación de la Ley) y sus cinco funciones específicas: Toma de denuncia; Investigar denuncia; Pronunciamiento de medidas cautelares; Aplicación medidas cautelares y Dictar sentencia, son realizadas por todos los sectores en un porcentaje entre un $4 \%$ y un 45\%. A excepción de Carabineros, que supera este porcentaje. (Figura N 3).

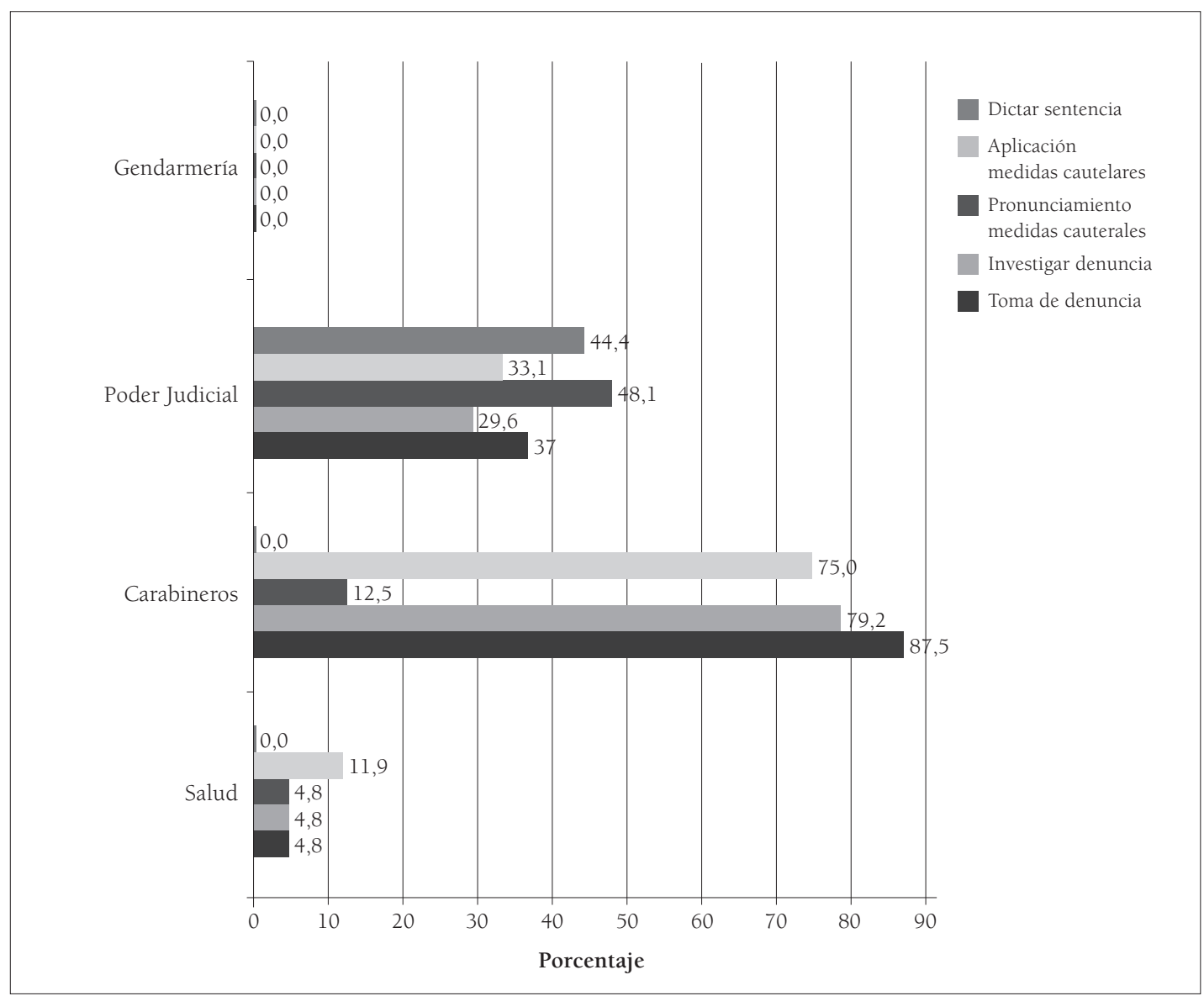

Fuente: elaboración propia.

Finalmente, en el ámbito de la prevención, es Carabineros quien desarrolla ampliamente estas funciones: Promoción (séptima función), Prevención (octava función), Capacitación (novena función),
Sensibilización (décima función) y Acciones comunicacionales (decimoprimero función) (Figura N 4) y (Figura N 5). 


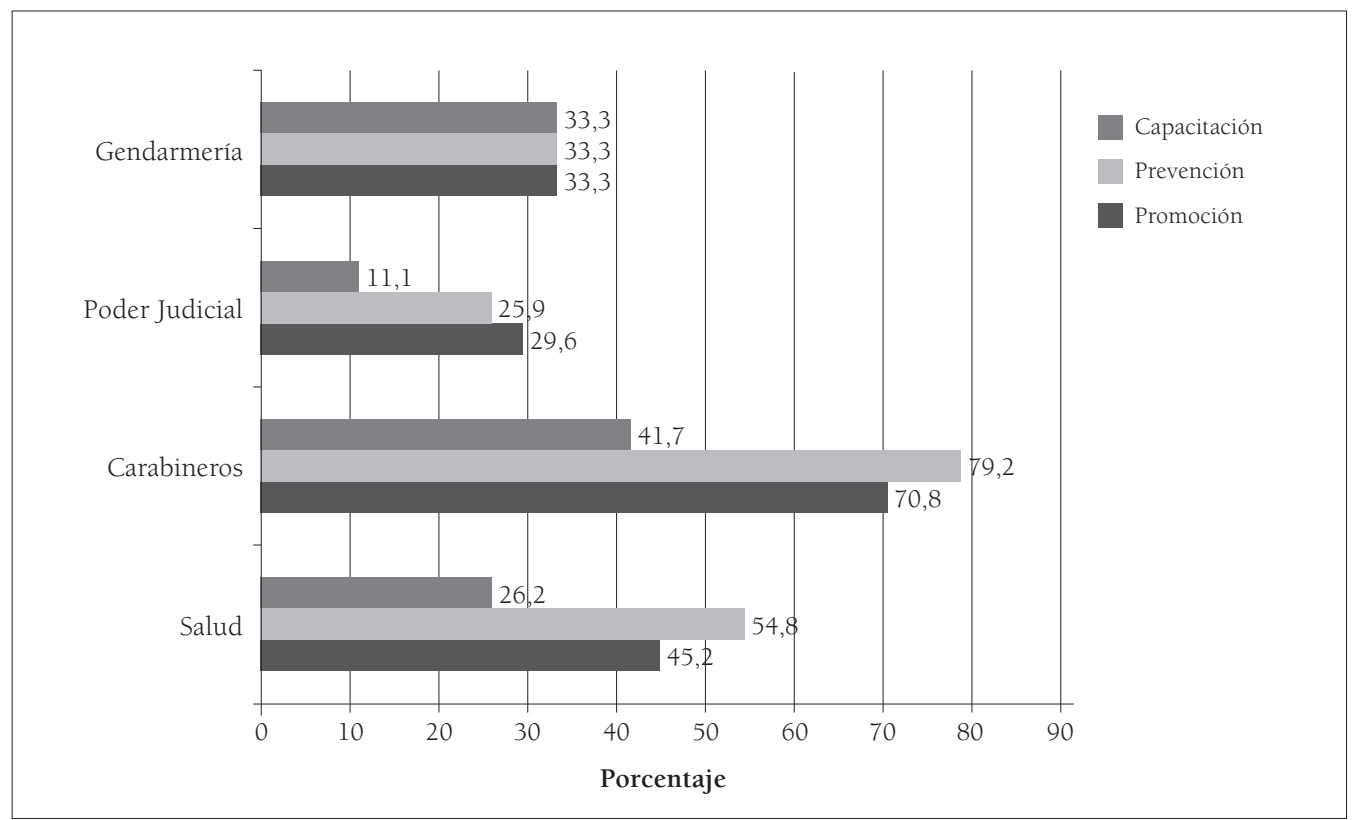

Fuente: elaboración propia.

FIGURA No 5

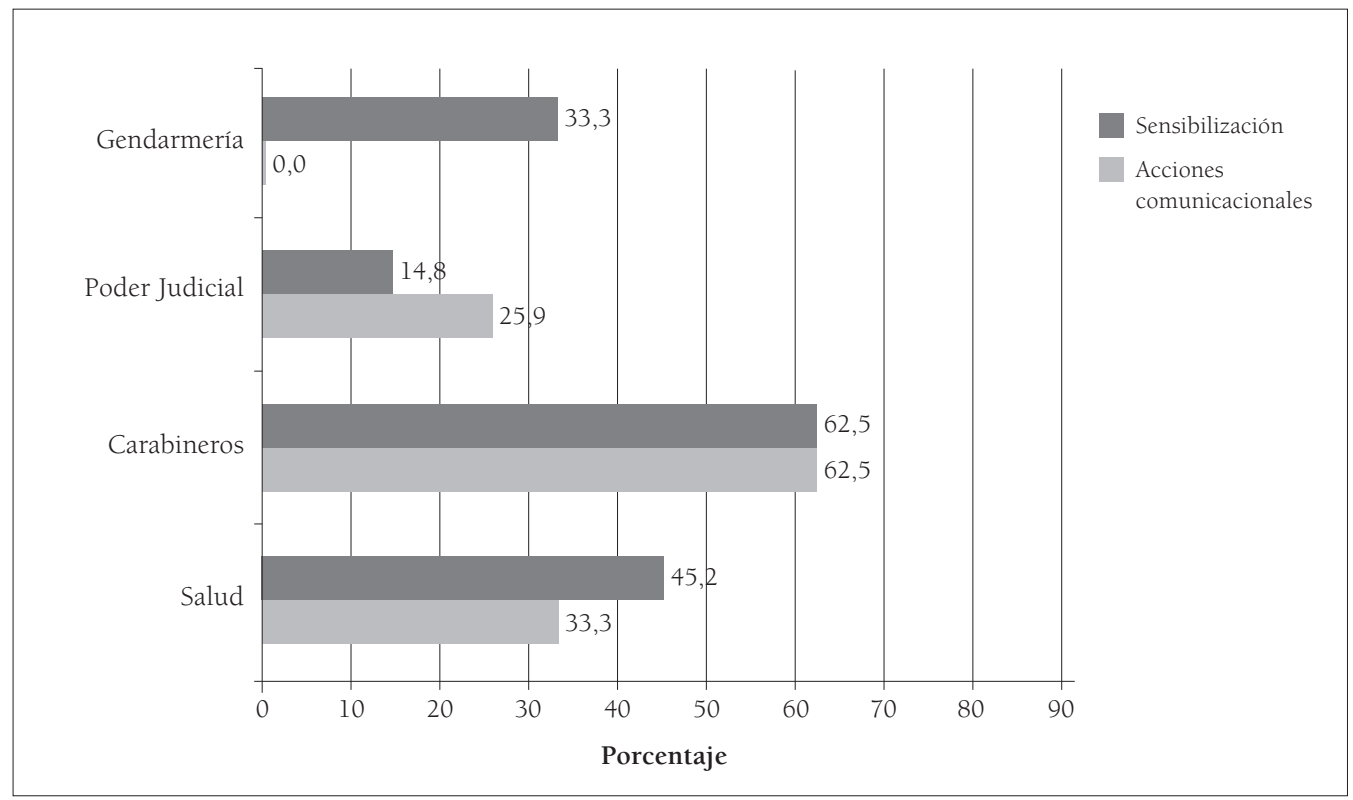

Fuente: elaboración propia.

Cuatro elementos constituyen los puntos centrales identificados por las autoridades entrevistadas respecto del escenario actual en materia de servicios destinados a hombres con comportamientos violentos hacia sus parejas: La inexistencia de una política pública, la consideración de la violencia ejercida por los hombres hacia sus parejas como una problemática social, la definición utilizada de esta y el marco legal. "yendo a un tema más macro, yo creo que hay una serie de diálogos en la sociedad chilena que no se dan, que absolutamente no están presentes en la agenda pública sino a nivel de caricatura, o sea estoy siendo muy duro, pero el tema de la violencia contra la mujer o los temas de género surgen a propósito de noticias y cuestiones que pasan..." (Defensoría Penal Pública). 
"...las drogas, el alcoholismo, es exactamente igual, son problemas globales, integrales, que se atacan en el colegio, se trabajan en la casa, en el trabajo, en las juntas de vecinos, le corresponde a las policias, a los organismos públicos, a todos, si es un problema social. Y ahí las políticas de Estado son las fundamentales, son las directrices..." (Fiscalía)

“...en algún minuto la autoridad política está de acuerdo con el lineamiento técnico o viceversa en términos de que la violencia de género es conceptualizada de determinada manera y por lo tanto dentro de ese paradigma no cabe la atención de los hombres" (Subsecretaría de Prevención del Delito, Seremi del Interior)

"...De hecho y ese es otro tema que se discute, la ley de VIF engloba situaciones distintas... la ley de VIF debe volver a estudiarse, precisamente... para separar las situaciones de violencia de género con el tema de violencia intrafamiliar, que es una situación que me parece son distintas" (Defensoría Penal Pública)

\section{Sistemas de derivación}

En las doce comunas que abarcó el estudio se informa la existencia de redes de coordinación. 64 instituciones $(66,6 \%)$ declaran conocer la existencia de redes, $28(29,1 \%)$ declaran que no existen redes y 4 instituciones $(4,2 \%)$ no saben/no responden. Del total de 96 instituciones, 56 (58,3\%) participan en red, $6(6,3 \%)$ no participan y $34(35,4 \%)$ no saben/no contestan. Cabe señalar que existen diferencias al comparar las 12 comunas que integran la Provincia de Concepción, lo cual se relaciona principalmente con la trayectoria (antigüedad) de trabajo según la estrategia de red y dinámicas propias de cada territorio.

Estas instancias de coordinación se traducen en mesas de trabajo o redes locales, las que permiten realizar acciones concertadas, derivar a un usuario para recibir atención específica, como generar instancias de auto capacitación. También existe un sistema de derivación interno, especialmente en salud y uno externo, enmarcado en la Ley 20.066, en donde se reciben y realizan derivaciones a diferentes organismos. Por ejemplo, si Carabineros recibe una denuncia, esta es derivada a los tribunales competentes. Cuando los Tribunales de Familia solicita un informe psicológico para recabar antecedentes en el proceso judicial se solicita principalmente a las instituciones de salud. Un tercer ejemplo es cuando algún profesional toma conocimiento de una situación de VIF, y encontrándose en la obligación de denunciarla, realiza una denuncia a Carabineros o a Tribunales de Familia para comenzar el proceso judicial.

Las autoridades de servicios entrevistadas exponen un escenario en donde, así como a nivel local, también existen instancias de coordinación a nivel regional, que pretenden aunar criterios y esfuerzos entre organismos para desarrollar una labor concertada. El accionar descrito del mismo modo se caracteriza por llevarse a cabo de manera parcelada, discontinuada, en donde se reconoce la existencia de duplicidad de esfuerzos. Estas acciones institucionales responden a prioridades del sector o a acuerdos con otros organismos pero no necesariamente a una política global.

"porque a nosotros nos pasa como salud una situación que es que por ejemplo el Sernam, que ve este tema y que es la mandatada a hacerse cargo del tema, nos convoca, pero después nos convoca la autoridad sanitaria, después nos convoca justicia, con toda la línea de atención de víctimas, entonces, estamos demandados de muchos sectores que de alguna manera están trabajando de forma independiente pero que convocan a los mismos" (Servicio de Salud Talcahuano).

"....tiene que ver con esto que decía yo de las parcelas del Estado, cada institución tiene su rol y lo ejecuta lo mejor que puede, sin embargo, mira un aspecto del fenómeno que en realidad está bien, sin embargo, a la hora de intervenir, genera muchas veces lagunas a la hora de responder a las personas". (Seremi de Justicia).

"en vez de optimizar los procesos sabiendo aprovechar los perfiles de cada una de las instituciones y la función que cada institución realiza, no lo hacen sino que aumentan el aparataje" (Corporación de Asistencia Judicial)

En el mismo sentido, se expone un desconocimiento respecto de la oferta pública. Los servicios que las demás reparticiones del Estado ofrecen no son claros para todos los organismos públicos relacionados o las solicitudes entre instituciones no siempre obtienen una respuesta favorable.

"necesitamos contacto con la red, necesitamos saber qué prestaciones hay, qué podemos ofrecerle a nuestros usuarios y cómo contactarnos fácilmente y rápidamente..." (Fiscalía) 
"acá hay un problema que el sistema no funciona, no está coordinado para poder trabajar en conjunto y para poder colocar esa protección humana que necesitan esas mujeres". (SERNAM) "pero para el caso de hombres agresores, si usted me dijera yo no sabría donde derivarlo... oye viene un hombre y dice, sabe que tengo problemas, no puedo contener la ira, necesito ayuda, no sé si hay lugares especializados donde pueda llamar y digan sí, sabe, mándelo para acá...yo creo que ahí lo que falta efectivamente, podría haber una coordinación en ese sentido con las instituciones que trabajan en esta área..." (Defensoría Penal Pública)

"...bueno, en relación con otras instituciones lo que nosotros hemos detectado es que los vasos comunicantes entre una y otra institución y los programas que manejan a veces no están coordinados" (Seremi de Salud)

"...de repente el equipo de salud mental nos dice: no, no tenemos la batería o no tenemos el personal habilitado para hacer un informe de personalidad de esta persona que nos pueda dar un constructo agresor...sobre todo para el tema diagnóstico..." (Tribunales de Familia)

\section{Obstaculizadores y facilitadores}

Se solicitó a las instituciones identificar fortalezas, debilidades y necesidades en el trabajo dirigido a hombres que ejercen violencia conyugal, en relación a: 1) la institución y 2) el territorio.

Las principales fortalezas de las instituciones en el trabajo con hombres que ejercen violencia hacia sus parejas son: "la voluntad y el compromiso con el trabajo en violencia intrafamiliar" (24), seguido de "contar con profesionales capacitados" (17). En el caso de las fortalezas identificadas en los territorios existentes, se identifican diferencias ligadas a dinámicas propias de cada territorio. En general podemos señalar que se identifican la "confianza de la comunidad hacia la institución" y la "buena coordinación con la red de Violencia Intrafamiliar".

Respecto de las debilidades identificadas en relación a las instituciones y el trabajo dirigido a hombres que ejercen violencia de pareja, para el sector Salud, Carabineros y Gendarmería, la principal debilidad es la "falta de capacitación en el tema", seguido de "no contar con programas". Para el sector judicial, la principal debilidad es "no contar con programas", seguido de la "falta de capacitación en el tema". (Figura N 6).

FIGURA N ${ }^{\circ} 6$

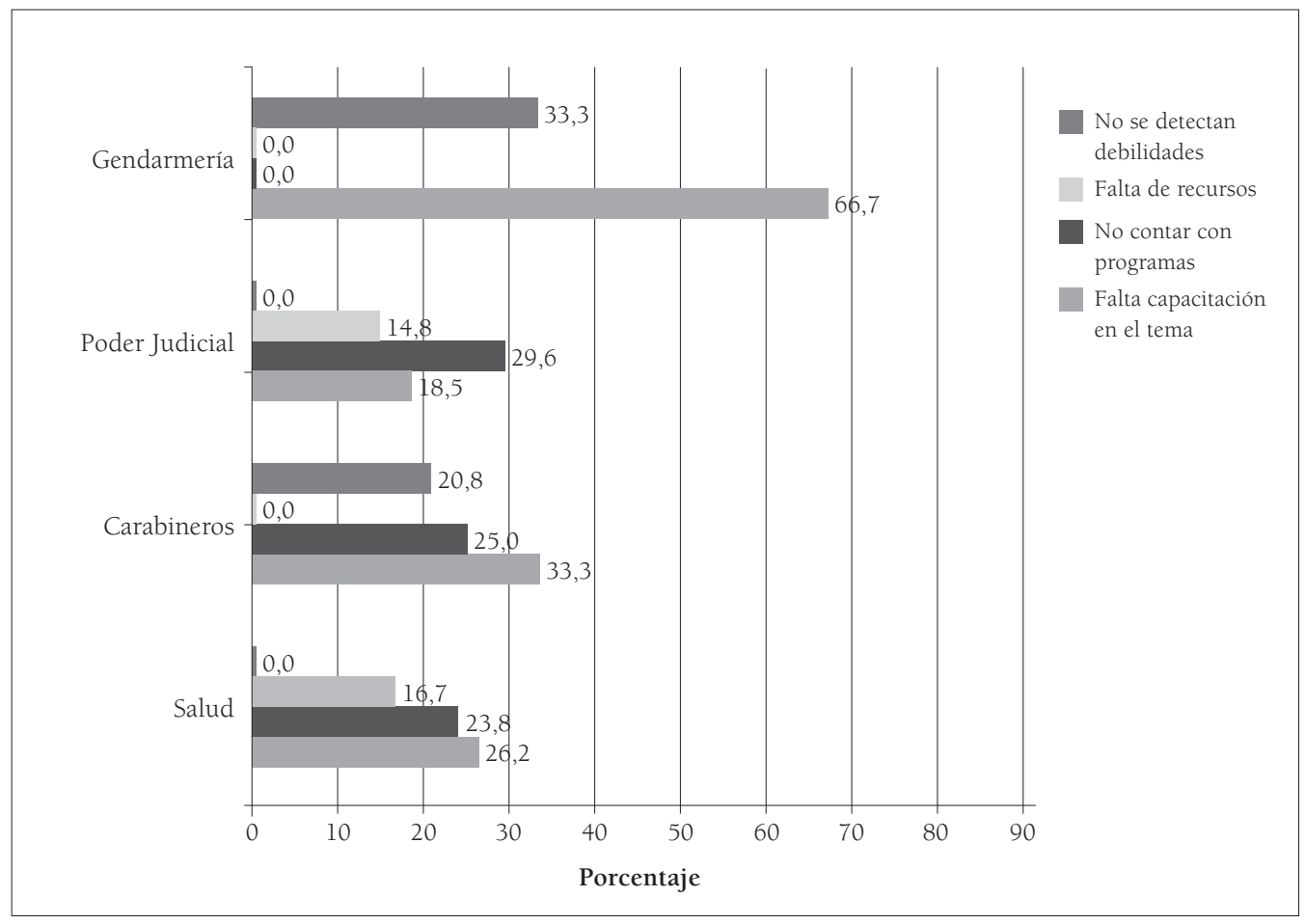

Fuente: elaboración propia. 
En cuanto a las debilidades identificadas en el territorio se mencionan: la "inexistencia de instituciones que trabajen la problemática" (25), en segundo lugar "la debilidad en el trabajo en redes" (15) y en tercer lugar, "la mentalidad machista" (11).

En relación a las necesidades detectadas en las instituciones, se priorizan de la siguiente manera: "existencia de programas especializados" (20), "mejorar el trabajo en redes" (13), "aumentar recursos" (6), la misma cantidad señala que "contar con profesionales especializados" y "cambio de legislación y/o políticas públicas" (4).

En el territorio se exponen las siguiente necesidades: "existencia de instituciones para agresores" (24), en segundo lugar, "mayor trabajo en red" (13), luego "mayores recursos" (11), en cuarta opción "promoción y prevención" (6).

Cabe señalar que en todas las categorías (detección de fortalezas, debilidades y necesidades) entre un $24 \%$ y un $36 \%$ de los servicios participantes respondió no sabe/no responde.

Dentro de los avances visualizados por las autoridades entrevistadas se encuentran: la comprensión de la violencia conyugal como problema social, los aprendizajes realizados y el personal capacitado.

"... yo creo que los avances tienen que ver con haber ido haciendo aprendizajes de cuáles son las necesidades desde el sector salud, de cuál es nuestra realidad" (Servicio de Salud Talcahuano)

"...el hecho de que se haya dictado desde la reforma que creó los tribunales de justicia y la ley 20.066 creo que el avance está en que se pueden hacer más cosas de las que se hacían antes de estas leyes, porque antes yo creo que era mucho más impersonal, en cambio cuando esas personas se enfrentan en una audiencia con el juez, hay compromisos verbales que se adoptan frente a la autoridad del juez" (Tribunal de Familia).

"la especialización del personal y específicos de fiscales en el área es súper relevante, o sea las fiscalías más grandes cuentan con personas que están abocadas a este tema...pero además a nivel de las provincias, cuando por ejemplo tenemos fiscalias... de menor tamaño, también hemos designado fiscales especializados en el área, de manera de abarcar provincialmente el tema, por lo menos en la materia de coordinación" (Fiscalía)
En cuanto a debilidades, a la insuficiencia de espacios de atención a hombres que ejercen violencia conyugal y a la desarticulación en el trabajo en red, se suman las escasas acciones en materia de prevención. Por un lado, los organismos del aparato judicial (Tribunales de Familia, Fiscalía y Defensoría) explican que es una labor que no les corresponde, que son mandatados a cumplir la ley, investigar, sancionar o defender al imputado pero no prevenir la ocurrencia de la problemática. Por otro, desde los organismos que actualmente desarrollan esta labor, esta responde a actividades que no necesariamente son mantenidas en el tiempo como estrategias eficientes que pretendan evitar que el uso de la violencia conyugal se mantenga o aumente.

"nosotros no tenemos un rol preventivo, ni hacemos análisis de la situación contextual, nuestra función es investigar el delito, que quede claro que ocurrió, formarnos convicción y ejercer la acción penal pública..." (Fiscalía)

"no es mi rol hacerlo, porque además hay una trampa en esto, que el Estado permanentemente le está traspasando al sistema de justicia criminal cuestiones que tienen que ver con políticas públicas, que son muy anterior a esas" (Defensoría Penal Publica)

"pero cuando uno piensa en lo que es la promoción y la prevención, cómo evitar que esto ocurra en la sociedad... ahí la cosa a nosotros se nos escapa a nosotros como salud" (Servicio de Salud Talcahuano)

"para nosotros eso es súper importante, poder sensibilizar, y creemos que una de las formas de sensibilizar es la formación de monitores...nos hemos acercado a scouts, a distintas iglesias, a los institutos profesionales, a los establecimientos de educación superior, para que la necesidad surja de ellos...el año pasado tratamos de reforzar también una línea de prevención y realizamos una actividad masiva con estudiantes, de colegios, de liceos, con el objeto de poder prevenir violencia en el pololeo" (SERNAM)

“...depende también de qué pensemos por prevención de la violencia intrafamiliar, de qué entendamos la dinámica relacional que hay detrás de la violencia intrafamiliar, que tampoco uno puede establecer cortes en el tiempo de cuándo se inicia la violencia, eso es muy difícil...entonces yo apostaría a pensar 
que tiene que ver con cómo nos relacionamos con los problemas... con cómo construimos sociedad, con cómo superamos la desigualdad, el tema de las oportunidades, y cómo entendemos el rol de las mujeres y los hombres y logramos convivir". (Subsecretaría de Prevención del Delito, Seremi del Interior)

La falta de recursos, la rotación de profesionales y la escasa especialización en la materia son obstáculos nombrados por las autoridades, además de la poca uniformidad de criterios en las sanciones judiciales que afectan la intervención y la calidad de esta.

"yo creo que lo que falta siempre, primero recursos, creo que siempre son escasos y se hacen pocos, hay que focalizarlos en determinadas áreas y en planes bien concretos donde podamos participar todos" (Fiscalía)

"... la falta de profesionales que tengan experticia en la temática, porque a veces se puede contar con un profesional pero que es generalista y que no sea experto" (Seremi de Justicia)

"como trabajamos en los tribunales de justicia, en realidad cada juez de familia tiene absoluta libertad para interpretar y aplicar la norma de la forma en que lo entienda, entonces en general, considerar que hayan políticas públicas que uno en realidad adopte como criterio general y aplicable por todos los jueces de familia, eso no es asî" (Tribunales de Familia)

"son los centros de salud, básicamente los equipos de salud mental han instalado trabajo para manejo de control de impulsos, para el tema de violencia intrafamiliar especifico, para otros problemas que pudieran estar asociados, como alcoholismo, drogas. Efectivamente son ellos los que se están llevando la carga y lamentablemente es un recurso muy escaso" (Tribunal de Familia)

Finalmente, un obstáculo que ha influido en la oferta del servicio público es el referido por las autoridades como características de los sujetos de intervención, relacionados a aspectos culturales y de género.

"...debemos recordar que estamos luchando contra una cultura ancestral donde la mujer tenía menos derechos y era casi normal, en cierta medida, llegar al abuso en lo que era el contexto de pareja y no existían estos mecanismos modernos de denuncia" (Seremi de Justicia) "también hemos tenido algunos hombres pero muy poquitos, y agresores, pero con el tiempo, cuando hemos ido evaluando, lo que nos dimos cuenta es que en realidad era un recurso que no se utilizaba eficientemente porque los agresores no van y cuando van lo hacen obligados, dependiendo de su situación y van una vez y después no vuelven a ir...la adherencia era muy baja..." (Servicio de Salud Talcahuano)

"a veces se da también que los hombres agresores por un tema de trabajo, no están permanentemente en la comuna y por lo tanto, se hace muy difícil el seguimiento efectivo de una terapia" (Tribunal de Familia).

"a ver, el gran obstáculo, no solo en esta institución sino que en todas las instituciones que atienden de una u otra manera este fenómeno es la reticencia del hombre a participar de programas ya sea preventivos o recuperativos en materia de VIF" (Seremi de Salud).

\section{Análisis y discusión}

El análisis conjunto de los cuestionarios y las entrevistas semiestructuradas permite explorar el objeto de estudio desde una mirada macro, en donde se discute acerca de los elementos que sustentan la (exigua) existencia de servicios hacia hombres que ejercen violencia hacia sus parejas en la Provincia de Concepción, es decir, aspectos conceptuales, marcos políticos y legales y las representaciones culturales. Así como una segunda mirada respecto del exosistema, es decir, de las instituciones y de las acciones concretas dirigidas a este grupo social.

Se expondrán de manera integrada entonces, aquellos elementos expuestos por los sujetos participantes, que permiten por un lado describir el estado actual del abordaje institucional en materia de hombres que ejercen violencia conyugal en la Provincia de Concepción y por otro, reflexionar en torno a los factores que podrían estar manteniendo dicho estado, considerando a los actores involucrados.

En primer lugar, se presenta el avance de concebir la violencia conyugal como un problema social, transversal, en donde todas las instituciones participantes del estudio declaran un rol que cumplir y un interés en disminuir su incidencia, los daños y costos que conlleva. Se plantea un camino realizado en donde con ciertas dificultades se ha logrado posicionar el abordaje de la problemática como una tarea de todos, lo que invita a centrar la mirada en la existencia de una política pública que persigue orientar el accionar. 
Siguiendo a Heclo (1974, citado en Merrien et al., 2005), si concebimos las políticas públicas como intentos de mejorar las políticas anteriormente adoptadas, en donde el acento estaría puesto en el proceso invención/aprendizaje de estas, podemos señalar que ha existido un proceso de aprendizaje que justamente ha permitido que todos los sectores perciban tener un rol frente al abordaje de la violencia conyugal. Sin embargo, es en el momento de implementar dichas orientaciones que no obstante los distintos esfuerzos que cada sector ha hecho, estas no permiten responder de manera integral ante la complejidad de la problemática, traduciéndose en una duplicidad de esfuerzos aislados que van en contra de lo que sostiene Smedslund (2014) respecto de la alianza cooperativa institucional, necesaria para responder a la violencia conyugal concebida como una problemática con raíces estructurales y sociales. Se ha instalado actualmente entonces una forma de intervenir sectorial y no integral, contraviniendo lo que plantean las personas que trabajan directamente con el tema.

Si actualmente existe claridad sobre que la violencia conyugal no es un problema privado sino uno público y que ha sido necesario legislar, desarrollar experticias, instalar institucionalidad y contar con profesionales especializados, probablemente ahora el desafío y aprendizaje se dirige en dos líneas interrelacionadas. Por un lado, analizar críticamente el paradigma desde el cual se ha construido conceptualmente la problemática, y en segundo lugar reflexionar sobre cómo este paradigma ha repercutido en una manera particular de intervenir. Si se comprende la violencia conyugal como un fenómeno diferente de la violencia intrafamiliar (lo que debería tener repercusiones legales como señalaba un informante), como un problema relacional entre hombres y mujeres y como un problema estructural que se refleja en prácticas individuales pero que se sostiene en aspectos culturales, entonces la manera de intervenir implementada actualmente requiere ser objeto de un análisis crítico de manera de instalar un proceso de invención/aprendizaje que permita responder adecuadamente a la problemática.

Cuando es analizado el estado actual del abordaje institucional destinado a hombres que ejercen violencia de pareja en la Provincia de Concepción, podemos visualizar claramente lo que venimos de exponer. Existe (señalado por los participantes) una ausencia de política pública dirigida a este grupo social, puesto que la violencia conyugal se ha comprendido como un problema en donde los hombres han estado omitidos como grupo foca- lizado de la política pública y por ende han sido invisibilizados como parte de la solución para erradicar la problemática. Entonces la falta de una política pública a este respecto reflejaría tanto la manera de comprender la problemática así como la forma de intervenirla.

Debemos recordar que al momento del levantamiento de información el SERNAM aún no implementaba el programa dirigido a hombres que ejercen violencia hacia sus parejas ("Programa hombres por una vida sin violencia"). Es desde 2012 que este se comienza (de manera gradual) a implementar en todo el país como una estrategia para abordar la problemática, lo que podemos visualizar como un aprendizaje en torno a la manera de conceptualizar la problemática que va por el camino de comprender que las acciones dirigidas a hombres que ejercen violencia conyugal son parte fundamental de la protección a las víctimas, de la responsabilización de quienes ejercen violencia conyugal (Lesiex et al., 2014) y de la modificación en las relaciones que los hombres establecen. Sin embargo, dos elementos merecen atención, primero la tendencia a continuar implementando acciones de tipo sectorial y no integral, en donde debiera concebirse la responsabilidad en el abordaje como una tarea de todo el aparato público y no de un sector solamente (como señaláramos más arriba, se plantean SERNAM, Gendarmería de Chile y la Municipalidad de Santiago como responsables de las acciones, no explicitándose la participación de otros sectores). En segundo lugar, cabe preguntarse de qué manera el Plan Nacional de Acción para la Prevención de la Violencia Intrafamiliar en Chile pretende abordar aquellos aspectos estructurales (culturales) identificados durante la investigación.

En este sentido, si profesionales y autoridades participantes conciben la violencia conyugal y el comportamiento violento de los hombres con sus parejas como un problema cultural, de hecho se plantea la "mentalidad machista" como una importante debilidad en el territorio, que es necesaria de cambiar, pero que difícilmente se modificará en base a actividades y acciones aisladas de cada sector o solo a través acciones dirigidas a individuos, entonces, la eficacia en la prevención y erradicación de este problema social estará dada por la existencia de una política que ordene el accionar institucional y a su vez por estrategias que apunten a abordar aquellas raíces profundas de la violencia conyugal.

Así, desde una perspectiva ecológica, si la violencia conyugal es entendida como una manera (desigual) de relacionarnos, entonces la política debiera 
apuntar a modificar aspectos de orden cultural (transformación en las relaciones de género, modificación de representaciones de violencia y cambio de la masculinidad hegemónica); institucional (instalar en todas las instituciones una mirada integral del problema así como dotar de recursos y de programas de intervención de largo plazo, con equipos profesionales en condiciones adecuadas de trabajo, en que intervenga la intersectorialidad) e individual-relacional (acciones dirigidas a los propios involucrados, que es lo que actualmente se está implementando), sin dejar de lado ninguno de estos tres niveles.

La profundidad de esta tarea implica modificar el paradigma que ha orientado la implementación de la política pública. Así, la influencia la ideología familiar en el Estado (Merrien, 2007) y la naturaleza de los lazos entre la esfera privada y la pública podrían ser factores que influenciarían el contenido de las políticas públicas en materia de violencia conyugal y por tanto el accionar del aparato público. Es decir, la consideración de la violencia que ocurre al interior de la pareja como un problema privado reforzaría la ausencia de un Estado regulador y garante de derechos. Por otro lado, comprender la violencia conyugal solo como un problema familiar o "de mujeres", repercutiría en el tipo de estrategias para abordarla, implementándose aquellas que no consideran los aspectos más amplios ni a quienes ejercen la violencia.

Entonces, por un lado, (como ya lo hemos señalado) se debe distinguir la violencia intrafamiliar de la violencia conyugal (puesto que deja fuera una serie de relaciones de pareja que viven violencia). En segundo lugar, superar una orientación centrada fundamentalmente en la reparación, que ha focalizado el accionar en las víctimas (mujeres), sin considerar una respuesta y una oferta real a los hombres que ejercen violencia conyugal (en donde no se debe confundir el dejar de continuar implementando programas de reparación, ni dotar de oferta pública para los hombres, restando recursos a los ya existentes para las mujeres víctimas de violencia conyugal ${ }^{12}$. En tercer lugar, sumar a la intervención de tipo terapéutico (dirigida a quienes vivencian directamente la problemática) el desarrollo de acciones preventivas, de sensibilización comunitaria o de movilización colectiva, de lo contrario se profundiza la "privatización" o la "despolitización" en la respuesta a este tipo de violencia (lo que abordaremos más adelante). En cuarto lugar, más allá de la función específica que cumple cada institución en relación a la problemática (sea que aborde los aspectos sanitarios, la aplicación de la ley, la persecución del delito, la defensa del imputado, la prevención del problema o la educación y promoción de relaciones igualitarias de género) debe reforzarse un marco orientador en el abordaje de la violencia conyugal y en específico de la intervención con hombres que ejercen violencia conyugal. A nuestro parecer dicho marco orientador es la política de igualdad de género, que en nuestro país lleva más de dos décadas implementándose y que la información recogida por parte de los(as) participantes poco alude a ella. Lo que podría reflejar una cierta desconexión de la violencia conyugal como una expresión de la desigualdad de género. Dicho de otra manera, un contexto desigual en materia de relaciones entre hombres y mujeres (PNUD, 2010) sienta la bases para la existencia de problemáticas como la violencia conyugal. Entonces una política que incluya acciones tendientes a la promoción de la equidad de género reforzaría las estrategias que pretenden la erradicación de la violencia conyugal. Sin embargo esta noción está marginalmente enunciada por los/as informantes.

Las ideas expuestas precedentemente se relacionan con un segundo elemento de análisis. Hablamos de la integralidad del abordaje, es decir, mirar la problemática en su conjunto y responder institucionalmente según este paradigma. La experiencia internacional ha apuntado a este aspecto para intervenir actualmente la violencia conyugal. Experiencias como las de España, Alemania, Austria (Smedslund, 2014), Nueva York (Harris, 2014) y Canadá (Lesieux, et al., 2014), exponen los cambios en materia legislativa, institucional (tribunales integrados), la adaptación de los programas y de los y las funcionarios/as a las características de los grupos sociales a los cuales están dirigidos. Son ejemplos de la aplicación de la visión estructural de la violencia y por ende de un cambio de paradigma que no ha estado exento de resistencias y de prejuicios ante la instalación de nuevas prácticas, pero que finalmente se instalaron como políticas que han intentado mejorar las directrices anteriormente adoptadas. Así, el pensar sectorialmente y desarrollar estrategias según este paradigma (cada sector hace lo suyo)

12 La ley establece la obligación de prevención y asistencia. Especialmente la prevención de la violencia contra la mujer, los adultos mayores y los niños/as y asistencia a las víctimas de la violencia. Dejando claramente fuera a los hombres como sujetos prioritarios de intervención (Plan Nacional de Violencia Intrafamiliar en Chile. Noviembre 2012-diciembre 2013). 
podría potenciar una intervención parcelada como la que caracteriza el contexto actual de la Provincia de Concepción.

Los resultados arrojaron que solo tres instituciones de un total de 96, implementan un programa dirigido a hombres que ejercen violencia conyugal. El sector salud lleva a cabo principalmente acciones de detección, primera acogida y atención individual. Carabineros desarrolla su quehacer por sobre el 70\% también en la detección, primera acogida, derivación a otras instituciones, orientación e información legal, toma de denuncia, investigación y aplicación de medidas cautelares. El sistema judicial por su parte, en un $70 \%$ deriva a otras instituciones y concentra su accionar en las funciones de asesoría legal y aplicación de la ley. Finalmente, Gendarmería, centraliza su quehacer (66\%) en detección del agresor, primera acogida, intervenciones individuales y grupales, participación en red, derivación e implementación y seguimiento de política pública. Se constata que el accionar global de las instituciones se concentra en una dimensión individual de la problemática, que podríamos pensar respondería a una lógica subyacente de la intervención actual. En este sentido, a excepción de Carabineros, las demás instituciones desarrollan en menos de un 45\% acciones de promoción, prevención y sensibilización.

El abordaje actual, entonces, estaría focalizado principalmente en el nivel individual-relacional, a través de talleres terapéuticos dirigidos a hombres que ejercen violencia hacia su pareja o la atención individual de estos. Lo que como señalábamos anteriormente, tendería a reforzar el carácter privado de la problemática (circunscrita a la relación de pareja o a la conducta del sujeto), en segundo lugar, invisibilizaría el carácter político de esta relación, es decir, que las relaciones entre hombres y mujeres son relaciones de poder, en donde el uso abusivo ejercido por los hombres se enmarca en un contexto cultural que lo refuerza, y en tercer lugar, se tornaría (un abordaje) insuficiente por cuanto las acciones de prevención y sensibilización, concebidas como aquellas principales en la transformación de los sustentos estructurales, entendidos culturales, de la problemática, no estarían siendo asumidas activamente por todas las instituciones.

A partir de las opiniones expuestas por los(as) informantes, es necesario implementar nuevas formas de intervención, que consideren la creación de programas especializados (siendo la más alta necesidad expuesta) con recursos suficientes; un trabajo de redes eficaz que implica un enfoque integral y no sectorial, la lógica que "cada uno hace lo suyo" merma los esfuerzos, invisibiliza los avances y no apunta al cambio mayor necesario para enfrentar los aspectos estructurales (culturales) de la problemática; la capacitación de recurso humano especializado, puesto que en Chile la intervención con hombres que ejercen violencia hacia sus parejas a $\mathrm{n}$ resulta ser un tema nuevo, debido a la escasa experiencia existente, la minima investigación realizada y la falta de sistematizaciones y evaluaciones de las prácticas que se han llevado a cabo. Dichas "necesidades" expuestas por los(as) participantes se insertan en la elaboración de una política pública que oriente claramente el accionar institucional. A nuestro parecer, la política pública además de promover una nueva forma de intervención (integral) debe apuntar a abordar aquellos aspectos sostenedores de la problemática.

Como ya hemos señalado, una nueva forma de pensar la violencia conyugal apuntaría a una nueva forma de abordarla, en donde la intervención con hombres que ejercen violencia conyugal sea parte integral de la oferta pública así como estrategias de promoción de una cultura del respeto y la igualdad. Ellos son algunos de los desafíos que se debe plantear el Estado, y la cualidad relacional que aporta la perspectiva de género permite no solo comprender e intervenir sobre la violencia conyugal que viven las mujeres sino también comprender e intervenir la violencia conyugal que ejercen los hombres. Por otro lado, este carácter relacional establece un estrecho vinculo entre lo individual y lo cultural, como dos dimensiones que se interrelacionan mutuamente. Será entonces, la voluntad política y la redefinición conceptual de la problemática como señalan Lesiex et al (2014) y Smedslund (2014) el factor principal para dar el cambio necesario a la forma de intervenir actualmente.

Finalmente, un tercer elemento de análisis apunta a los sujetos de intervención (hombres que ejercen violencia conyugal) en donde las representaciones que los profesionales así como la autoridad han construido de este, confirma lo planteado por la literatura, siendo los aspectos que sobresalen de ellos: la resistencia a participar en los programas terapéuticos (Turcotte, 2014) y el rol de proveedores que dificulta su participación por falta de tiempo. Estas características han influenciado el abordaje institucional, en donde se ha restringido la "oferta" pública debido a la "baja demanda". Desde una mirada ecológica y según la perspectiva de género, estas prácticas masculinas no son posibles de considerar como conductas individuales, por el contrario, se enmarcan en un contexto que elabora mecanismos para mantenerlas. 
En el mismo sentido, si la violencia conyugal se sostiene en base a la desigualdad de género y a la construcción social de la masculinidad hegemónica sostenida en el abuso de poder, el Estado chileno tiene un gran desafío en abordar el contexto (cultural), las instituciones (y sus propias resistencias culturales) y las practicas de los/as propios actores que intervienen y que refuerzan esta masculinidad y estas relaciones entre hombres y mujeres, considerando que las representaciones de género machistas y autoritarias y la clara ausencia de los hombres en los cambios ligados a las relaciones de género caracterizan el contexto chileno (PNUD, 2010).

La representación de "la clientela" es un factor que emerge entre las respuestas y los relatos de los/as participantes como un elemento que obstaculiza el accionar y en donde muchas veces las instituciones se han habituado a dichas "cualidades", restringiendo recursos, disminuyendo equipos o claramente cerrando programas, debido a la "baja demanda" o "baja adherencia" presentada por dicho grupo. Lo anterior, no hace sino fortalecer la masculinidad a la que hacíamos referencia y esta relación "institución-cliente" es reforzada, a su vez, por la ausencia de acciones que trasformen nuestra cultura en donde la solicitud de ayuda es sinónimo de debilidad/ feminidad.

Incorporar entonces a los hombres como sujetos de una política pública integral y la promoción de una masculinidad que se construya desde la igualdad y no desde el abuso estarán altamente conectados a las estrategias pensadas para erradicar la violencia conyugal.

\section{Conclusiones}

Según los resultados obtenidos por este estudio, el accionar institucional en materia de abordaje con hombres que ejercen violencia hacia su pareja se caracteriza por exponer un escenario de política pública que no incluye conceptual e integralmente a los hombres como sujetos de política pública (siendo incorporados después de llevado a cabo el estudio); un enfoque sectorial que debilita los esfuerzos realizados y los resultados obtenidos; una cantidad de servicios insuficientes teniendo en cuenta la prevalencia del problema y una práctica centrada en el nivel individual-relacional que no aborda los aspectos estructurales sostenedores de la problemática.
Los desafíos, por tanto, a considerar, apuntan a la práctica (resistencias, limitaciones y oportunidades) que realizan las instituciones de la Provincia de Concepción así como al cambio de paradigma desde un nivel político-conceptual, en donde se lleve a cabo una discusión amplia y profunda de la manera de ver la problemática y concebir estrategias a largo plazo promoviendo un cambio estructural que apunte a la igualdad de género. Es necesario para ello continuar profundizando en estudios posteriores respecto de si los aprendizajes que se han hecho han significado las modificaciones necesarias para responder de manera pertinente a la problemática estudiada ${ }^{13}$.

\section{Bibliografía}

- ADAMS, D. (1988), Treatment models of men who batter: A profeminist analysis. In K. Yllo \& M. Bograd (Eds.), Feminist perspectives on wife abuse, (pp. 176199). Newbury Park, CA: Sage.

- ANDRÉS-PUEYO, A., LÓPEZ, S., \& ÁlVAREZ, E. (2008). Valoración del riesgo de violencia contra la pareja por medio de la SARA. Papeles de Psicólogo, 29, 107-122.

- BRONFENBRENNER, U. (1979) La ecología del desarrollo humano, Barcelona: Paidos.

- CONNELL, R. (1995), The Social Organization of Masculinity. Berkeley, University of California Press.

- CORPORACIÓN DOMOS (2009), Catastro Centros de Atención a hombres que ejercen violencia hacia la mujer, Santiago de Chile. (sn).

- CORPORACIÓN DOMOS (2010), Perspectivas y desafios del trabajo con hombres que ejercen violencia hacia las mujeres en la pareja. Santiago de Chile. (sn).

- CENTRO DE INVESTIGACIÓN INTERDISCIPLINARIA SOBRE LA VIOLENCIA FAMILIAR Y LA VIOLENCIA HACIA LAS MUJERES (CRI-VIFF) Obtenida 16 de junio de 2014, desde: http://www.criviff. qc.ca

- DAMANT, D. \& GUAY, F. (2005), La question de la symétrie dans les enquêtes sur la violence dans le couple et les relations amoureuses. The Canadian Review of Sociology and Anthropology, 42(2), 125-144.

- DIVISIÓN DE SEGURIDAD PÚBLICA DEL MINISTERIO DEL INTERIOR (2013), Encuesta Nacional de Victimización por Violencia Intrafamiliar y Delitos Sexuales. Obtenida 10 de junio de 2014,desde:http:// www.seguridadpublica.gov.cl/filesapp/Presentacion\%20VIF_adimark_final.pdf

13 Al momento de escribir este artículo el Centro de Hombres Bio Bio implementado por Gendarmería se había cerrado. Abriéndose un nuevo centro dependiendo de SERNAM "Centros para Hombres por una Vida Sin Violencia ". Establecido en el Plan Nacional de acción para la prevención de la violencia intrafamiliar en Chile 2012-2013. (www.sernam.cl). 
- HARRIS, J. (2014), La réponse de l'État de New York à la violence conjugale, au trafic sexuel et aux autres formes de violence envers les femmes. Dans Rinfret-Raynor, M., Lesieux, É., Cousineau, M-M., Gauthier et Harper, E. (Eds), Violence envers les femmes. Réalités complexes et nouveaux enjeux dans un monde en transformation. (pp. 291-306). Québec: Presses de l'Université du Québec.

- JOHNSON, M. (2005), Domestic Violence: It's not about gender - or is it?. Journal of marriage and family, $67,1126-1130$

- LAVERGNE, C. (1998), Analyse du processus de construction de la violence faite aux femmes en contexte conjugal comme problème socio-pénal au Québec. Revue fermmes et droit / Canadian Journal of Women and the Law (10), 377-399.

- LESIEUX, É., RINFRET-RAYNOR, M., ET BRODEUR, N., (2014), Le développement des services d'aide en maison d'hébergement pour femmes victimes de violence conjugale au Québec, de 2004 à 2009. Dans Rinfret-Raynor, M., Lesieux, É., Cousineau, M-M., Gauthier et Harper, E. (Eds), Violence envers les femmes. Réalités complexes et nouveaux enjeux dans un monde en transformation. (pp. 259-274). Québec: Presses de l'Université du Québec.

- LINDSAY, J., ET CLÉMENT, M. (1998) La violence psychologique : sa définition et sa représentation selon le sexe. Dans Nouvelles questions féministes. Recherches féministes Vol 11(2). (p.139-160).

- LOSEKE, D., \& KURZ, D. (2005), Men's violence toward women is a the serious social problem. In D., Loseke, R., Gelles \& M., Cavanaug (Eds), Current controversies on family violence. (pp.79-95). Thousand Oaks, CA : Sage Publications.

- MERRIEN, F-X, PARCHET, R. \& KERNEN, A., (2005), L'État social. Une perspective internationale. Paris: Armand Colin.

- MERRIEN, F-X., (2007) L'État-Providence. Paris: Presses Universitaires de France.

- MORAleS, A., MUÑOZ, N., TRUJIllo, M., HURTADO, M., CÁRCAMO, J. Y TORRES, J. (2012), LOS programas de intervención con hombres que ejercen violencia contra su pareja mujer. Gendarmería de Chile/Fundación Paz Ciudadana. Santiago de Chile (sn).

- PLAN NACIONAL DE VIOLENCIA INTRAFAMILIAR EN CHILE. (Septiembre 2011- Agosto 2012) Obtenida 10 de junio de 2014, desde: http:// www. sernam.cl/descargas/plan_nacional_vif.pdf

- PlAN NACIONAL DE VIOLENCIA INTRAFAMILIAR EN CHILE. (Noviembre 2012-Diciembre 2013). Obtenida 10 de junio de 2014, desde: http://www.sernam.cl/descargas/Plan_Nacional_2012-2013.pdf

- PROGRAMA DE LAS NACIONES UNIDAS PARA EL DESARROLlO, PNUD (2010) Desarrollo Humano en Chile 2010. Género: Los desafíos de la igualdad. Santiago: PNUD.
- SERVICIO NACIONAL DE LA MUJER (SERNAM) (2011) (2013) (2014) En: http://www.sernam.cl

- REPÚbliCA DE CHILE. Ley No 19.325 publicada en el Diario Oficial 27 de agosto 1994. Obtenida 16 de junio de 2014, desde: http://www.leychile.cl/ Navegar?idNorma $=242648$

- REPÚbliCA DE CHILE. Ley No 20.066 publicada en el Diario Oficial 7 de octubre 2005. Obtenida 16 de junio de 2014, desde: http://www.leychile.cl/ Navegar?idLey $=19325$

- SCOTT, J., (1996) El género: una categoría útil para el análisis histórico. En Marta Lamas (comp) El género: la construcción cultural de la diferencia sexual. (pp.265302). PUEG, México.

- SMEDSLUND, K., (2014), Évaluation de pratiques innovantes en matière de lutte contre les violences conjugales en Allemagne, en Autriche et en Espagne. Dans Rinfret-Raynor, M., Lesieux, É., Cousineau, M-M., Gauthier et Harper, E. (Eds) Violence envers les femmes. Réalités complexes et nouveaux enjeux dans un monde en transformation. (pp. 275-290). Québec: Presses de l'Université du Québec.

- STARK, E. (2014), Une re-présentation des femmes battues. Contrôle coercitif et défense de la liberté. Dans Rinfret-Raynor, M., Lesieux, É., Cousineau, M-M., Gauthier et Harper, E. (Eds) Violence envers les femmes. Réalités complexes et nouveaux enjeux dans un monde en transformation. (pp. 15-32). Québec :Presses de l'Université du Québec.

- STITH, S., SMITH, D., PENN, C., WARDA, D., \& TRITTET, D. (2004). Intimate partner physical abuse perpetration and victimization risk factors: a meta-analytic review. Aggression and violent behavior. 10 : 65-98.

- STRAUS, M., (2005). Women's violence toward men is a serious social problem. (2005). In Loseke, D., Gelles, R \& Cavanaug, M. (Eds), Current controversies on family violence. (pp.57-77). Thousand Oaks, CA: Sage Publications.

- SUBSECRETARÍA DE PREVENCIÓN DEL DELITO. MINISTERIO DEL INTERIOR Y SEGURIDAD PÚBLICA (2014). Obtenida 16 de junio de 2014, desde: http://www.seguridadpublica.gov.cl/delitos_de_violencia_intrafamiliar_historico.html

- TURCOTTE, P. (2014) La ayuda a los hombres en violencia conyugal: del control al cambio personal y social (TraducciónTatiana Sanhueza). La manzana, IX(13). Extraído el 9 de julio de 2014 desde: http://www.estudiosmasculinidades.buap.mx/num13/violencia.htm

- YLlÖ, K. (1988). Political and Methodological Debates in Wife Abuse Research. In K. Yllö \& M. Bograd (Eds), Feminist Perspectives on Wife Abuse. (pp.28-50). Newbury Park, CA: Sage. 